earlier civilizations, the higher parts of the ridge scored by the winds so that only stunted bushes and grass could grow. A descent to Chachapoyas, $7638 \mathrm{ft}$., strengthened the travellers to cross the Calla Calla Pass; then the descent to the Maranon River, whence the Amazon falls $3000 \mathrm{ft}$. to the sea in about as many miles. Again a further pass and finally the last part of the journey by motor along the completely bare and barren coastal plain.
There is little of scientific interest in this book of a plant-collector ; but its simplicity, complete honesty and pleasant sense of humour cause it never to weary. The reader will form a better idea of this almost forgotten country from it than from a more pretentious work. The task of opening it up, with its numerous parasitic diseases and its unwanted products, is enough to depress any Government.

\title{
APPLIED AERODYNAMICS
}

\section{Applied Aerodynamics}

By Prof. L. Bairstow. Second edition. Pp. xviii $+808+27$ plates. (London, New York and Toronto: Longmans, Green and Co., 1939.) $63 s$. net.

7 HE first edition of this book was reviewed in NATURE of March 25, 1920. In general the appearance of a second edition of a standard textbook calls for little comment, but in the present case the changes are so far-reaching that the book is practically a new work. The period immediately before and during the War of 1914-18 was one of intensive pioneer research both on the theoretical and experimental side, and in this research Bairstow took a leading part. The first edition, based on the work done during that period, omits allreference to boundary layer theory, the Kutta and Joukowski theory of two-dimensional aerofoils, the circulation theory of lift, and the Lanchester-Prandtl theory of finite aerofoils. All this is remedied in the present edition, and for that reason alone it can be seen that the author's statement that about three quarters of the book is new material is easily justified.

The author has adhered to the general plan of the first edition, namely, to provide principles to interpret the results of experience, and to give adequate experimental results to illustrate the subject-matter.

The book opens with a short but interesting chapter on the history of the development of applied aerodynamics. Then follow chapters on the principles of flight, aerodynamic measurements, laboratory tests, aerial manœuvres, similarity and scale effect. The next five chapters start from first principles to build up the theory of aerofoils at moderate speeds when compressibility of the air is unimportant, and at high speeds when the properties of aerofoils are materially different from those at low speeds. These chapters contain detailed development of a large amount of ordinary hydrodynamical theory, potential, viscous, and two-dimensional boundary layer flow, including the detailed application to an actual aerofoil. There is also a short chapter introducing the statistical theory of turbulence.

The three remaining chapters deal with airscrews, performance, and stability. In connexion with stability the author explains that during the past twenty years economic pressure has led to intensive activity directed to increase of speed and load, and as a consequence a very large amount of information is available from which to choose illustrative examples of steady flying. The experimental investigation of more complex motions has been less thoroughly pursued and in particular there has been less systematic study. It has therefore not been possible to use modern examples to illustrate adequately the principles of stability, and for these sections the examples of the first edition have been retained. Nevertheless, an account of Glauert's non-dimensional system of equations would have been welcome here, as developed, for example, in the excellent study of stability given by B. Melvill Jones in volume 5 of Durand's "Aerodynamic Theory".

In the preface the author states that this book is in no sense an attempt to produce a text-book of designs, but aims at the extraction from the great mass of data of those elements which necessarily form the basis of all design. That this aim has been attained in full measure cannot be doubted. The book is full of apt numerical tables, graphs, and diagrams. There are also twenty-seven excellent plates, including one of the kite balloons now so prominent in the sky of London and elsewhere. Incidentally, an interesting conclusion from the investigation of the aerodynamic force on these balloons, is that the balloon is blown to a definite position by light winds, and will then maintain this position as the wind velocity increases.

The reviewer may perhaps be permitted two grumbles: (i) the apparent absence of definitions of common terms such as aspect ratio and camber, (ii) the very high price of this excellent volume.

\section{M. Milne-Thomson.}

